\title{
Implementation strategy fidelity evaluation for a multidisciplinary Chest Injury Protocol (ChIP)
}

Sarah Kourouche ${ }^{1 *}$ D , Kate Curtis ${ }^{1,2,3}$, Belinda Munroe ${ }^{1,4}$, Michael Watts ${ }^{5}$, Sharyn Balzer ${ }^{6}$ and Thomas Buckley ${ }^{1}$

\begin{abstract}
Background: Blunt chest wall injuries can lead to complications, especially without early intervention. A blunt Chest Injury Protocol (ChIP) was developed to help improve the consistency of evidence-based care following admission to the emergency department. Implementation strategy fidelity is the extent to which the strategies of implementation are delivered in line with the intended plan. The aim of this study was to assess fidelity to the strategies of the implementation plan developed for ChIP.

Methods: A retrospective evaluation of strategies used for implementation was performed, specifically the behaviour change techniques (BCTs). BCTs were used as part of an implementation plan derived based on the Behaviour Change Wheel from results from a staff survey at two hospitals.

Levels of implementation or adaptation for BCTs were scored by implementers as follows: 'Were the behaviour change interventions implemented?' ( 0 = 'not implemented', $1=$ partially implemented, and $2=$ fully implemented); 'Were adaptations made to the implementation plan?', scored 1 (many changes from plan) to 4 (just as planned). Free text explanation to their responses was also collected with supporting evidence and documentation (such as emails, implementation checklists, audit reports, and incident reports).

Results: There was high overall fidelity of $97.6 \%$ for BCTs partially or fully implemented. More than three quarters $(32 / 42,76.2 \%)$ of the BCTs were fully implemented with an additional 9/42 (21.4\%) partially implemented. BCTs that were not fully implemented were social support, feedback on behaviour, feedback on outcomes of behaviour, adding objects to the environment, and restructuring the environment. The modes of delivery with poorer implementation or increased adaptations were clinical champions and audit/feedback.
\end{abstract}

Conclusions: This study describes the evaluation of implementation strategy fidelity in the acute care context. The systematic use and application of the behaviour change wheel was used to develop an implementation plan and was associated with high implementation strategy fidelity. A fidelity checklist developed during the implementation process may help implementers assess fidelity.

Trial registration: Trial registered on ANZCTR. Registration number ACTRN12618001548224, date approved 17/09/ 2018

\footnotetext{
* Correspondence: Sarah.Kourouche@sydney.edu.au

${ }^{1}$ Faculty of Medicine and Health, Sydney Nursing School, The University of

Sydney Susan Wakil School of Nursing and Midwifery, 88 Mallet St,

Camperdown, NSW, Australia

Full list of author information is available at the end of the article
}

(c) The Author(s). 2021 Open Access This article is licensed under a Creative Commons Attribution 4.0 International License, which permits use, sharing, adaptation, distribution and reproduction in any medium or format, as long as you give appropriate credit to the original author(s) and the source, provide a link to the Creative Commons licence, and indicate if changes were made. The images or other third party material in this article are included in the article's Creative Commons licence, unless indicated otherwise in a credit line to the material. If material is not included in the article's Creative Commons licence and your intended use is not permitted by statutory regulation or exceeds the permitted use, you will need to obtain permission directly from the copyright holder. To view a copy of this licence, visit http://creativecommons.org/licenses/by/4.0/ The Creative Commons Public Domain Dedication waiver (http://creativecommons.org/publicdomain/zero/1.0/) applies to the data made available in this article, unless otherwise stated in a credit line to the data. 
Keywords: Implementation strategy, Intervention fidelity, Process evaluation, Behaviour change, Emergency, nursing, Injury, Blunt chest wall injury, Care bundle

\section{Contributions to the literature}

- Implementation research should include focus on evaluations of fidelity including evaluation of the implementation plan to improve the internal and external validity of implementation. Implementation strategy fidelity evaluates the extent to which implementation strategies were used to help determine the relationship between the implementation plan and success of the intervention.

- Retrospective review is possible for implementation strategy fidelity evaluation in the acute care context.

- The findings in this study contribute to recognised gaps in the literature, including how implementation researchers should address implementation strategy fidelity.

\section{Background}

Blunt chest wall injury, such as fractured ribs, can lead to serious health complications like pneumonia if not managed appropriately [1]. To improve the consistency of care for patients with blunt chest wall injury and minimise their risk of complications, an evidence-informed protocol was developed [2]. This protocol incorporated the best available evidence, included an early notification mechanism, and guided clinicians on management. Implementation strategies were developed using the Theoretical Domains Framework and the Behaviour Change Wheel $(\mathrm{BCW})[3]$ to facilitate implementation at two hospitals in regional Australia [4]. The BCW is a framework based on behaviour change theory that can help address clinician behaviour change [3]. Using theoretical frameworks is important, especially for a high acuity environment such as the emergency department with multidisciplinary teams [5]. Though the use of a framework improves the quality of the implementation strategies, evaluation of the fidelity of implementation is required to determine the relationship between the implementation plan and the success of the intervention [6].

Implementation strategy fidelity is the extent to which implementation strategies were used [7]. This contrasts with the fidelity of delivery (or treatment fidelity), which is the extent to which an intervention is delivered in line with the intended plan [7-9]. Fidelity of delivery is an evaluation of what was delivered clinically, whereas implementation strategy fidelity evaluates how the plan was delivered [10]. The delineation is often unclear in the literature and only referred to as implementation fidelity which encompasses both the fidelity of delivery and implementation strategy fidelity [11].

Generally, evaluation of implementation fidelity allows for comparisons between studies and allows for replication by ensuring that implementation is occurring as intended [9]. Differences in delivery can impact the effects of an intervention between sites, and fidelity can help control for this [12]. Fidelity is critical to the internal and external validity of implementation [7]. Fidelity is important for exploring the mechanisms through which change occurs [13].

Despite its importance, evaluation of implementation fidelity is rarely reported within intervention trials [10]. A survey of complex healthcare interventions identified that frameworks were not used by almost $70 \%$ of implementers in research reporting [8]. Some have suggested that this may be due to limited comprehensiveness of frameworks and language for evaluating implementation fidelity [7, 14]. Furthermore, there is little consensus on how to assess for fidelity [7].

There have been multiple frameworks suggested for implementation fidelity in the implementation literature. Among these, five main concepts have been described for implementation fidelity: adherence to an intervention, dose or exposure, programme delivery, participant engagement, and programme differentiation $[9,15,16]$. However, there is also contention as to whether these all are needed for fidelity evaluation [17]; furthermore, some are not relevant to the acute care setting. The aim of this study was to assess fidelity to the strategies of the implementation plan developed for ChIP. This paper is part of a larger study evaluating ChIP for patient, health service, and cost outcomes and for fidelity of delivery [18]. This is in the manuscript preparation stage. The fidelity of delivery has been evaluated separately [19]. The treatments within the protocol are all evidence-based and reflect other existing pathways that have been demonstrated to be effective [20].

\section{The intervention}

A care bundle was developed through an integrative review of chest injury interventions from 81 studies [2]. Care bundles are an intervention based on three to five key interventions combined [21]. The blunt chest injury care bundle was based on four main pillars of care: respiratory adjuncts, regular analgesia regime, complication prevention, and surgical fixation tailored to each patient within the context of their presentation [2]. The care bundle was adapted for the 
sites as surgical fixation was not possible due to a lack of trained staff and operating resources (Fig. 1). The blunt chest injury care bundle was called 'ChIP' (Chest Injury Protocol) for implementation for ease in remembering and use.

ChIP was designed for use by the multidisciplinary team and activated in the emergency department (ED). ChIP provided a guide for assessing the patient with blunt chest injury in the ED and a process for activation of an early notification system. The relevant clinicians were then expected to review the patient within $60 \mathrm{~min}$ and initiate care tailored to the individual. The responding clinicians included physiotherapy; the surgical, intensive care, pain teams; and, if required, the general medicine or geriatric team. After hours, the response required was slightly different. While the surgical, pain, and intensive care teams still reviewed the patient, the physiotherapist and aged care team reviewed the patient as a priority the following day.

The ChIP policy was opened for review and comment to the local health district. Any staff from the local health district could comment and give feedback on ChIP. Furthermore, direct feedback was sought on the intervention from staff and departments involved in the implementation. As a result, minor changes were integrated, such as adding pager numbers and contacts.

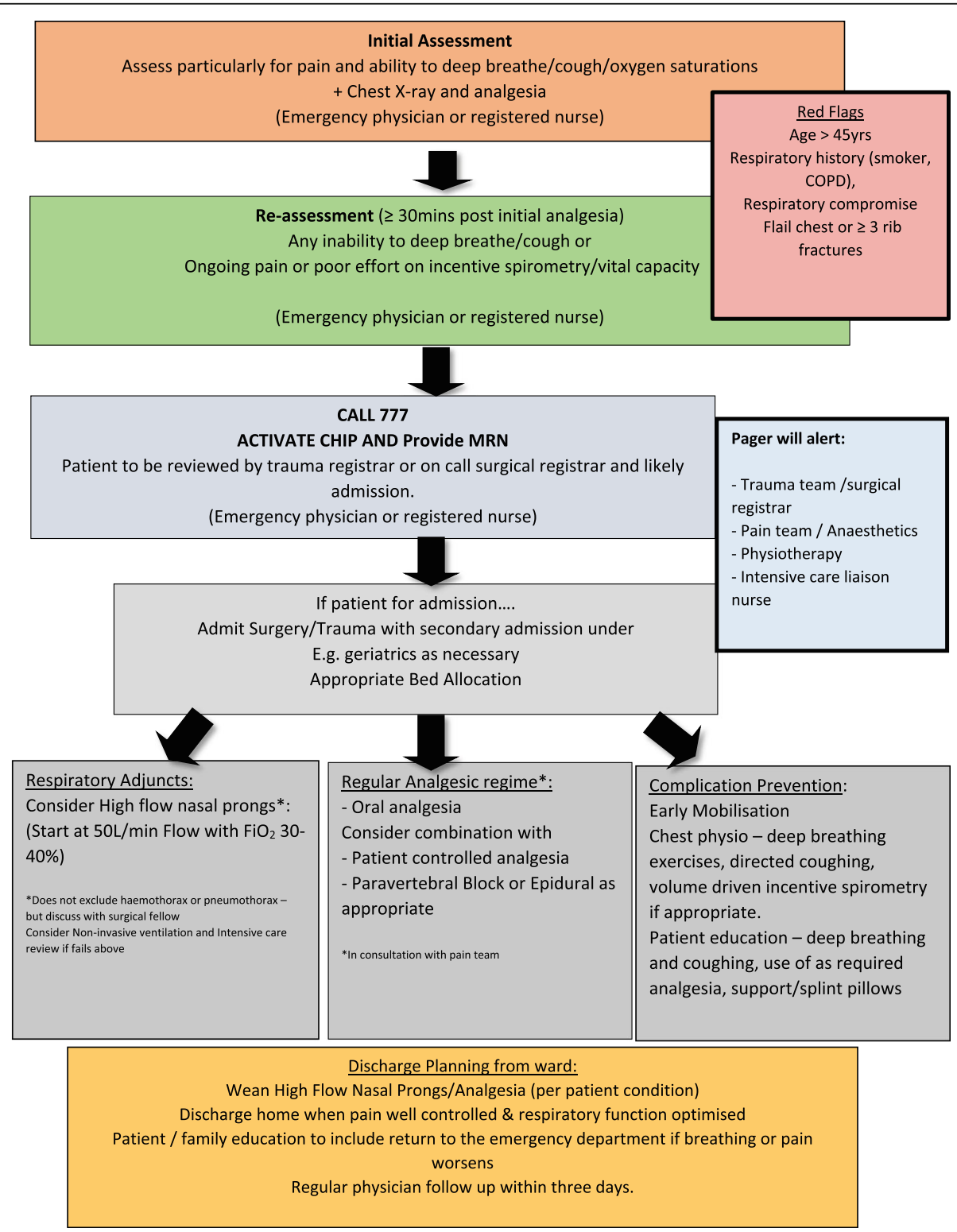

Fig. 1 The blunt chest injury care bundle (ChIP) 


\section{The implementation plan}

Implementation of ChIP commenced 22 November 2017 using an implementation plan developed using the $\mathrm{BCW}$ [3]. In previously published work, authors surveyed staff from 12 departments across two sites to identify facilitators and barriers to behaviour change [22]. The survey was informed by the Theoretical Domains Framework and identified nine facilitators and six barriers to implementation across eight domains [22]. An eight-step process based on the $\mathrm{BCW}$ was followed. The facilitators and barriers from the survey were mapped to intervention functions, behaviour change techniques (BCTs), and modes of delivery [22]. These were used to identify a mechanism of action often referred to as implementation strategies in the literature. BCTs are the active ingredients of change provided in a theory-linked taxonomy [6] and are defined within a taxonomy [23]. The BCTs can act as a coding framework for evaluation [24].

Each step was reviewed against the Affordability, Practicability, Effectiveness and cost-effectiveness, Acceptability, Side-effects or safety and Equity (APEASE) criteria [6]. Intervention functions are broad categories by means of which an intervention can change behaviour', and modes of delivery are the mediums through which the BCTs are delivered, such as media or guidelines [6]. The mechanisms of action combine the BCTs and modes of delivery into an actionable step. The complete implementation plan is available as an additional file [see Additional file 1]. Due to the high theoretical basis, following the implementation plan and the strategies outlined in the plan should result in higher fidelity and sustainability of the ChIP intervention. Strategies such as staff appearing in the ChIP video were intended to enable high fidelity and acceptability of implementation (Table 1) [25].

The implementation plan was discussed with stakeholders in a series of meetings at both sites. Implementers met with the managers for each department involved and presented the plan at education meetings to get feedback. It was reviewed and approved by key implementation team members and stakeholders. The stakeholders included business sponsors, executive sponsors (such as critical care directors, directors of nursing, physiotherapy district manager), trauma committee, end users, and managers from surgical, intensive care, ED, general medicine, geriatrics, and physiotherapy.

The implementation plan was designed to target BCTs and intervention functions through strategic mechanisms of action to address facilitators and barriers. The main modes of delivery for these mechanisms of action were a video featuring staff from the sites promoting ChIP, face-to-face educational sessions, prompts including an icon on the electronic medical record, other advertising such as flyers and emails, clinical champions, and audit/feedback. Resources were prepared and developed for each of these areas before implementation by the implementation team. The name ChIP served well as a theme of implementation, for example, putting potato chips near flyer advertisements for ChIP and using packets of chips (British-crisps) as the icon for the electronic medical record. A timeline of preparation and implementation is in Table 2.

The resources developed by the intervention developers prior to implementation commencement and the plans for the modes of delivery per the implementation plan are now more fully described per the behaviour change taxonomy [23] with further detail as recommended by Proctor et al. [26]. These are summarised in Table 1, including the barriers and facilitators that guided the inclusion [22]. The results evaluate these plans.

\section{Modes of delivery to operationalise the implementation plan}

Video A video was developed to address six BCTs and the intervention functions of incentivisation, enablement, training, education, persuasion, and modelling. The intervention development team produced the video following a simple storyboard. It featured multidisciplinary junior and senior staff to show the commitment and approval across the board to ChIP. The video featured demonstrations of the instructions that were required by the staff when implementing ChIP, modelling the behaviour required. The footage was filmed and edited by the implementation team using a smartphone and accessible video software. The video was uploaded to a private YouTube account for easy access by the implementation team. The planned dose was for the video to be shown during educational sessions, targeting each of the disciplines involved and added to all communications, including emails for the duration of the implementation period and new staff. The video was short, at less than 2 min long. The footage took staff through an example of using ChIP and the intervention options available featuring staff from various roles (Fig. 2). The video used can be viewed here https://youtu.be/VlMz1PjzmBk.

Visual prompts Visual prompts were developed for the ChIP rollout addressing three BCTs and intervention functions of education, persuasion, enablement, and environmental restructuring. Flyers were developed for the wards and the ED; these would be placed around the departments before implementation commencement by the implementation team. Email drafts were developed for the various departments involved by the implementation team. Patient flyers were also developed for patients 
Table 1 Behaviour change techniques (including their relevant numbers from the taxonomy), intervention functions, modes of delivery (bold), examples of the mechanisms of action, expected dose, and intended implementation outcome

\begin{tabular}{|c|c|c|c|c|c|}
\hline BCTs & $\begin{array}{l}\text { Intervention } \\
\text { functions }\end{array}$ & Mechanism of action & $\begin{array}{l}\text { Target barrier(s)/facilitator(s) (TDF } \\
\text { domain) }\end{array}$ & Expected dose & $\begin{array}{l}\text { Intended } \\
\text { implementation } \\
\text { outcome }\end{array}$ \\
\hline $\begin{array}{l}1.9 . \\
\text { Commitment }\end{array}$ & $\begin{array}{l}\text { Incentivisation, } \\
\text { enablement }\end{array}$ & $\begin{array}{l}\text { Staff appear in a video promoting } \\
\text { ChIP }\end{array}$ & $\begin{array}{l}\text { Remembering to use protocol } \\
\text { (memory, attention, and decision } \\
\text { processes) }\end{array}$ & $\begin{array}{l}\text { At least one } \\
\text { staff member } \\
\text { from each of } \\
\text { the disciplines } \\
\text { involved }\end{array}$ & $\begin{array}{l}\text { Increase fidelity/ } \\
\text { acceptability from } \\
\text { all disciplines }\end{array}$ \\
\hline $\begin{array}{l}\text { 2.2. Feedback } \\
\text { on behaviour }\end{array}$ & $\begin{array}{l}\text { Education, } \\
\text { persuasion, } \\
\text { incentivisation }\end{array}$ & $\begin{array}{l}\text { Staff compliance monitored through } \\
\text { audits and staff will be informed of } \\
\text { the results informally by clinical } \\
\text { champions, through newsletters } \\
\text { and emails }\end{array}$ & $\begin{array}{l}\text { Belief of consequences of care } \\
\text { bundle (belief about consequences) } \\
\text { Understanding of evidence-informed } \\
\text { interventions for a patient with blunt } \\
\text { chest injury (knowledge) }\end{array}$ & $\begin{array}{l}\text { Audits to be } \\
\text { done monthly } \\
\text { for } 12 \text { months }\end{array}$ & Increase fidelity \\
\hline $\begin{array}{l}\text { 2.7. Feedback } \\
\text { on outcome(s) } \\
\text { of behaviour }\end{array}$ & $\begin{array}{l}\text { Education, } \\
\text { incentivisation, } \\
\text { training }\end{array}$ & $\begin{array}{l}\text { Feedback given to staff from audit } \\
\text { results on patients treated with the } \\
\text { care bundle through clinical } \\
\text { champions }\end{array}$ & $\begin{array}{l}\text { Understanding of evidence-informed } \\
\text { interventions for a patient with blunt } \\
\text { chest injury (knowledge) } \\
\text { Belief of consequences of care } \\
\text { bundle (belief about consequences) } \\
\text { Emotions relating to commencing } \\
\text { new protocol (emotion) } \\
\text { Remembering to use protocol } \\
\text { (memory, attention, and decision } \\
\text { processes) } \\
\text { Confidence in patient assessment } \\
\text { skills (physical skills) }\end{array}$ & $\begin{array}{l}\text { For audits after } \\
1,2 \text {, and } 3 \\
\text { months then if } \\
\text { issues }\end{array}$ & $\begin{array}{l}\text { Increase } \\
\text { sustainability }\end{array}$ \\
\hline $\begin{array}{l}\text { 3.1. Social } \\
\text { support }\end{array}$ & Enablement & $\begin{array}{l}\text { Clinical champions chosen from } \\
\text { each area receive extra training to be } \\
\text { able to provide extra support }\end{array}$ & Social supports (social influences) & $\begin{array}{l}2 \text { clinical } \\
\text { champions from } \\
\text { each ED }\end{array}$ & Increase fidelity \\
\hline $\begin{array}{l}\text { 4.1. Instruction } \\
\text { on how to } \\
\text { perform } \\
\text { behaviour }\end{array}$ & Training & $\begin{array}{l}\text { Staff receive instructions on } \\
\text { behaviour via a video, educational } \\
\text { sessions, and clinical champions }\end{array}$ & $\begin{array}{l}\text { Confidence in patient assessment } \\
\text { skills, confidence in skills needed for } \\
\text { evidence-informed management of } \\
\text { blunt chest injury, adequate skill in } \\
\text { regional analgesia prescription and } \\
\text { management (physical skills) } \\
\text { Remembering to use protocol } \\
\text { (memory, attention, and decision } \\
\text { processes) }\end{array}$ & $\begin{array}{l}\text { Education } \\
\text { sessions to be } \\
\text { attended by } \\
\text { staff }\end{array}$ & Increased fidelity \\
\hline $\begin{array}{l}\text { 5.1. Information } \\
\text { about health } \\
\text { consequences }\end{array}$ & $\begin{array}{l}\text { Education, } \\
\text { persuasion }\end{array}$ & $\begin{array}{l}\text { Staff informed about the } \\
\text { improvement in pneumonia rate } \\
\text { reduction with the protocol from the } \\
\text { previous study through video, } \\
\text { educational sessions, flyers, }\end{array}$ & $\begin{array}{l}\text { Belief of consequences of care } \\
\text { bundle (belief about consequences) } \\
\text { Understanding of evidence-informed } \\
\text { interventions for a patient with blunt } \\
\text { chest injury (knowledge) }\end{array}$ & All relevant staff & $\begin{array}{l}\text { Increased } \\
\text { acceptability }\end{array}$ \\
\hline
\end{tabular}

newsletters,

6.1. Training,

Demonstration modelling

of behaviour
Staff receive demonstrations of behaviour via a video, educational sessions, and clinical champions
6.3. Information Education, about others' persuasion approval

$\begin{array}{ll}\text { 7.1. Prompts/ } & \text { Education, } \\ \text { cues } & \text { environmental }\end{array}$

Local staff appear in the ChIP video showing support

A visual prompt (screen icon) developed for the electronic medical
Confidence in patient assessment skills, confidence in skills needed for evidence-informed management of blunt chest injury, adequate skill in regional analgesia prescription and management (physical skills)

Remembering to use protocol (memory, attention, and decision processes)

Identify with professional role associated with care of blunt chest injury patients (professional/social role and identity)

Emotions relating to commencing new protocol (emotion)

dentify with professional role associated with care of blunt chest injury patients (professional/social role and identity)

Remembering to use protocol (memory, attention, and decision
All relevant staff Increased fidelity

$\begin{array}{ll}\begin{array}{ll}\text { Senior staff from } \\ \text { each discipline }\end{array} & \begin{array}{l}\text { Increase } \\ \text { acceptabilty }\end{array} \\ & \\ \begin{array}{ll}\text { On computer } \\ \text { system }\end{array} & \begin{array}{l}\text { Increase fidelity } \\ \text { and sustainability }\end{array}\end{array}$


Table 1 Behaviour change techniques (including their relevant numbers from the taxonomy), intervention functions, modes of delivery (bold), examples of the mechanisms of action, expected dose, and intended implementation outcome (Continued)

\begin{tabular}{|c|c|c|c|c|c|}
\hline BCTs & $\begin{array}{l}\text { Intervention } \\
\text { functions }\end{array}$ & Mechanism of action & $\begin{array}{l}\text { Target barrier(s)/facilitator(s) (TDF } \\
\text { domain) }\end{array}$ & Expected dose & $\begin{array}{l}\text { Intended } \\
\text { implementation } \\
\text { outcome }\end{array}$ \\
\hline & restructuring & $\begin{array}{l}\text { record to flag to staff that patient is } \\
\text { eligible for care bundle }\end{array}$ & processes) & & \\
\hline & & $\begin{array}{l}\text { Flyers put up around the workplace } \\
\text { to remind staff of the care bundle }\end{array}$ & & $\begin{array}{l}\text { In both EDs, } \\
\text { ICUs, trauma } \\
\text { wards }\end{array}$ & Increase fidelity \\
\hline $\begin{array}{l}\text { 8.3. Habit } \\
\text { formation }\end{array}$ & Training & $\begin{array}{l}\text { Staff encouraged to assess all } \\
\text { potentially eligible patients } \\
\text { systematically in the video and } \\
\text { educational sessions }\end{array}$ & $\begin{array}{l}\text { Confidence in patient assessment } \\
\text { skills, confidence in skills needed for } \\
\text { evidence-informed management of } \\
\text { blunt chest injury, adequate skill in } \\
\text { regional analgesia prescription and } \\
\text { management (physical skills) } \\
\text { Remembering to use protocol } \\
\text { (memory, attention, and decision } \\
\text { processes) }\end{array}$ & $\begin{array}{l}\text { Staff from } \\
\text { relevant } \\
\text { disciplines }\end{array}$ & Increase fidelity \\
\hline $\begin{array}{l}\text { 9.1. Credible } \\
\text { source }\end{array}$ & Persuasion & $\begin{array}{l}\text { Senior local staff appear in a video } \\
\text { informing staff about and promoting } \\
\text { ChIP }\end{array}$ & $\begin{array}{l}\text { Identify with professional role } \\
\text { associated with care of blunt chest } \\
\text { injury patients (professional/social } \\
\text { role and identity) }\end{array}$ & $\begin{array}{l}\text { At least one } \\
\text { staff member } \\
\text { from each } \\
\text { discipline }\end{array}$ & $\begin{array}{l}\text { Increase } \\
\text { acceptability }\end{array}$ \\
\hline \multirow[t]{4}{*}{$\begin{array}{l}\text { 12.1. } \\
\text { Restructuring } \\
\text { the physical } \\
\text { environment }\end{array}$} & \multirow[t]{4}{*}{$\begin{array}{l}\text { Environmental } \\
\text { restructuring, } \\
\text { enablement }\end{array}$} & $\begin{array}{l}\text { Equipment necessary for ChIP } \\
\text { placed in a location that ensures } \\
\text { ease of access }\end{array}$ & \multirow{4}{*}{$\begin{array}{l}\text { Remembering to use protocol } \\
\text { (memory, attention, and decision } \\
\text { processes) } \\
\text { Access to protocol, the protocol } \\
\text { design, access to equipment } \\
\text { (environmental context and } \\
\text { resources) } \\
\text { Emotions relating to commencing } \\
\text { new protocol (emotion) }\end{array}$} & $\begin{array}{l}\text { HFNC machines } \\
\text { and incentive } \\
\text { spirometry in } \\
\text { ED }\end{array}$ & Increase fidelity \\
\hline & & $\begin{array}{l}\text { Equipment adequately labelled with } \\
\text { instructions }\end{array}$ & & $\begin{array}{l}\text { All new HFNC } \\
\text { machines }\end{array}$ & Increase fidelity \\
\hline & & $\begin{array}{l}\text { Additional equipment supplied to } \\
\text { ensure adequate supply (high-flow } \\
\text { machines and incentive spirometry) }\end{array}$ & & & \\
\hline & & $\begin{array}{l}\text { ChIP tested by staff to ensure ease of } \\
\text { use }\end{array}$ & & $\begin{array}{l}\text { Tested once } \\
\text { prior to go live }\end{array}$ & Increased fidelity \\
\hline \multirow[t]{2}{*}{$\begin{array}{l}\text { 12.5. Adding } \\
\text { objects to the } \\
\text { environment }\end{array}$} & \multirow[t]{2}{*}{$\begin{array}{l}\text { Environmental } \\
\text { restructuring, } \\
\text { enablement }\end{array}$} & $\begin{array}{l}\text { An icon added for the electronic } \\
\text { medical record to flag to staff that } \\
\text { patient is eligible for care bundle }\end{array}$ & $\begin{array}{l}\text { Remembering to use protocol } \\
\text { (memory, attention, and decision } \\
\text { processes) } \\
\text { Access to protocol (environmental } \\
\text { context and resources) } \\
\text { Emotions relating to commencing } \\
\text { new protocol (emotion) }\end{array}$ & $\begin{array}{l}\text { Add prior to go } \\
\text { live }\end{array}$ & Increased fidelity \\
\hline & & $\begin{array}{l}\text { A pager setup to be able to contact } \\
\text { staff responding to ChIP }\end{array}$ & & $\begin{array}{l}\text { Set up prior to } \\
\text { go live }\end{array}$ & Increased fidelity \\
\hline $\begin{array}{l}13.1 . \\
\text { Identification } \\
\text { of self as a role } \\
\text { model }\end{array}$ & $\begin{array}{l}\text { Persuasion, } \\
\text { enablement }\end{array}$ & $\begin{array}{l}\text { Staff asked to volunteer for the roles } \\
\text { of clinical champions and to be in } \\
\text { the video }\end{array}$ & $\begin{array}{l}\text { Emotions relating to commencing } \\
\text { new protocol (emotion) } \\
\text { Identify with professional role } \\
\text { associated with care of blunt chest } \\
\text { injury patients (professional/social } \\
\text { role and identity) }\end{array}$ & $\begin{array}{l}\text { Champions at } \\
\text { each site }\end{array}$ & $\begin{array}{l}\text { Increased fidelity } \\
\text { and sustainability }\end{array}$ \\
\hline $\begin{array}{l}\text { 15.1. Verbal } \\
\text { persuasion } \\
\text { about } \\
\text { capability }\end{array}$ & $\begin{array}{l}\text { Persuasion, } \\
\text { enablement }\end{array}$ & $\begin{array}{l}\text { Staff encouraged during educational } \\
\text { sessions and by clinical champions } \\
\text { that they are capable of following } \\
\text { ChIP }\end{array}$ & $\begin{array}{l}\text { Emotions relating to commencing } \\
\text { new protocol (emotion) }\end{array}$ & At each session & $\begin{array}{l}\text { Increased fidelity } \\
\text { and acceptability }\end{array}$ \\
\hline
\end{tabular}

Definitions for intervention functions: Education: increasing knowledge or understanding, Persuasion: using communication to induce positive or negative feelings or stimulate action, Incentivisation: creating an expectation of reward, Training: imparting skills, Environmental restructuring: changing the physical or social context, Modelling: providing an example to aspire to, Enablement: increasing means/reducing barriers

who had received a ChIP call by the implementation team. Newsletter items were also prepared, adjusted based on where they would be displayed and who would be seeing them. They included eye-catching advertisements using a 'ChIP logo' of a packet of chips. Notices were prepared to be placed in the clinical communication books.

Facilitators/clinical champions Facilitators/clinical champions addressed eight BCTs and intervention 
Table 2 Implementation of ChIP timeline, monitoring, and stakeholder roles

\begin{tabular}{|c|c|c|}
\hline Date & What & Who \\
\hline $\begin{array}{l}18 \text { October } \\
2017\end{array}$ & Policy online as draft for comment & ED CNC \\
\hline $\begin{array}{l}20 \text { October } \\
2017\end{array}$ & Research nurse hired & ED CNC/implementation team \\
\hline $\begin{array}{l}23 \text { October } \\
2017\end{array}$ & High-flow nasal cannula (HFNC) machines labelled with instructions & ED CNC \\
\hline October 2017 & Filming for video by the implementation team & $\begin{array}{l}\text { Implementation team, staff from } \\
\text { departments involved }\end{array}$ \\
\hline $\begin{array}{l}25 \text { October } \\
2017\end{array}$ & Item prepared for surgical staff newsletter & ED CNC/implementation team \\
\hline $\begin{array}{l}26 \text { October } \\
2017\end{array}$ & Video Version 1 & Implementation team \\
\hline $\begin{array}{l}30 \text { October } \\
2017\end{array}$ & $\begin{array}{l}\text { Video Version } 2 \\
\text { Training materials (including PowerPoint) developed } \\
\text { Chip packets for staff tearoom } \\
\text { Notices prepared for newsletter }\end{array}$ & Implementation team \\
\hline $\begin{array}{l}31 \text { October } \\
2017\end{array}$ & $\begin{array}{l}\text { Organise dates and instructors for educational sessions for } \\
\text { - Ward } \\
\text { - ICU } \\
\text { - ED } \\
\text { - Surgical registrars } \\
\text { - Anaesthetic } \\
\text { - Physiotherapists }\end{array}$ & Implementation team \\
\hline $\begin{array}{l}6 \text { November } \\
2017\end{array}$ & $\begin{array}{l}\text { Implementation plan final } \\
\text { Draft emails for each department organised } \\
\text { Advertising flyers prepped }\end{array}$ & Implementation team \\
\hline $\begin{array}{l}7 \text { November } \\
2017\end{array}$ & Final version of ChIP video completed and uploaded to YouTube channel & Implementation team \\
\hline $\begin{array}{l}7 \text { November } \\
2017\end{array}$ & $\begin{array}{l}\text { Email went out to all staff, managers } \\
\text { Except site } 2\end{array}$ & Implementation team/managers \\
\hline $\begin{array}{l}13 \text { November } \\
2017\end{array}$ & Premature ChIP activation at site 1, went smoothly & ED staff \\
\hline $\begin{array}{l}15 \text { November } \\
2017\end{array}$ & Incentive spirometers ordered & $\mathrm{ED} C \mathrm{CNC}$ \\
\hline $\begin{array}{l}16 \text { November } \\
2017\end{array}$ & $\begin{array}{l}\text { Discussion re role of ICU liaison: } \\
\text { - Education for ward, switch, and bed manager } \\
\text { - Audit switch pagers and check compliance } \\
\text { - Ensure education for new surgical/ICU and anaesthetic registrars is sustainable, will } \\
\text { incorporate ChIP into hospital orientation sessions. }\end{array}$ & Implementation team \\
\hline $\begin{array}{l}20 \text { November } \\
2017\end{array}$ & $\begin{array}{l}\text { Stakeholders approve policy } \\
\text { Organise educational sessions to be delivered }\end{array}$ & $\begin{array}{l}\text { Stakeholders-executives, managers, } \\
\text { etc. } \\
\text { Fisher \& Paykel } \\
\text { Implementation team }\end{array}$ \\
\hline $\begin{array}{l}21 \text { November } \\
2017\end{array}$ & $\begin{array}{l}11 \text { new pagers programmed and tested with all of their existing capcodes plus the new } \\
\text { capcode allocated for } 880\end{array}$ & Implementation team \\
\hline $\begin{array}{l}22 \text { November } \\
2017\end{array}$ & Go live date & \\
\hline $\begin{array}{l}22 \text { November } \\
2017\end{array}$ & First patient has ChIP activated at site 2 (without electronic medical record being active) & \\
\hline $\begin{array}{l}23 \text { November } \\
2017\end{array}$ & Consult Clinical Pathway order for ChIP is available in FirstNet for site 2 & \\
\hline $\begin{array}{l}23 \text { November } \\
2017\end{array}$ & Contract for casual RN (clinical champion) processed & \\
\hline $\begin{array}{l}27-28 \\
\text { November } \\
2017\end{array}$ & $\begin{array}{l}\text { Based on feedback: } \\
\text { - PowerPoint presentation edited to include how to chart HFNP } \\
\text { - Videos updated-both updated to include patient education, incentive spirometer, how to } \\
\text { chart HFNC }\end{array}$ & Implementation team \\
\hline
\end{tabular}


Table 2 Implementation of ChIP timeline, monitoring, and stakeholder roles (Continued)

\begin{tabular}{|c|c|c|}
\hline Date & What & Who \\
\hline & - A dedicated 'cheat sheet' algorithm for site 2 as their notification process is different & \\
\hline $\begin{array}{l}30 \text { November } \\
2017\end{array}$ & Queries from surgical staff regarding charting of HFNC and observations & \\
\hline $\begin{array}{l}4 \text { December } \\
2017\end{array}$ & $\begin{array}{l}15 \text { educational sessions more provided this week } \\
\text { ChIP in nursing grand rounds this week } \\
\text { Some issues with HFNC being charted to medication chart_-education regarding same }\end{array}$ & Implementation team \\
\hline $\begin{array}{l}5 \text { December } \\
2017\end{array}$ & Switched incentive spirometers to volume-driven devices & Physiotherapy/implementation team \\
\hline $\begin{array}{l}1 \text { February } \\
2018\end{array}$ & 44 ChIP notifications since November & \\
\hline $\begin{array}{l}6 \text { February } \\
2018\end{array}$ & $\begin{array}{l}\text { Fact sheet for patients and contacts at site } 2 \text { added to electronic medical record (emailed } \\
27 / 11 / 17 \text { ) }\end{array}$ & Implementation team \\
\hline
\end{tabular}

Abbreviations: ChIP Chest Injury Protocol, CNC clinical nurse consultant, ED emergency department, eMR electronic medical record, ICU intensive care unit

functions of education, persuasion, training, modelling, incentivisation, and enablement. The implementation plan fostered consistent messaging and implementation across sites. Facilitators played an essential role in the implementation plan as strong facilitators can drive implementation and enable change [27]. The ED clinical nurse consultants (CNCs) played the role of facilitator at the two sites. Discussions with facilitators at sites frequently occurred (several times per week) at peak times and less frequently (once a fortnight) during other times. The facilitators for the implementation of ChIP were part of the existing workforce of the hospitals and in positions where they would be able to facilitate the change as part of their roles. Furthermore, one of the strategies used within the implementation plan was to employ clinical champions at each site to improve the consistency of implementation. Clinical champions were to be employed by the emergency $\mathrm{CNC}$ using research funding for 3 months.

Audit and feedback Audit and feedback addressed two BCTs and intervention functions education, persuasion, and incentivisation. Feedback during the implementation process was to be sought through formal and informal measures. Formal feedback measures included audits, incident reports, and morbidity and mortality meetings. Informal feedback measures included informal discussions with staff. The plan was for the intensive care unit

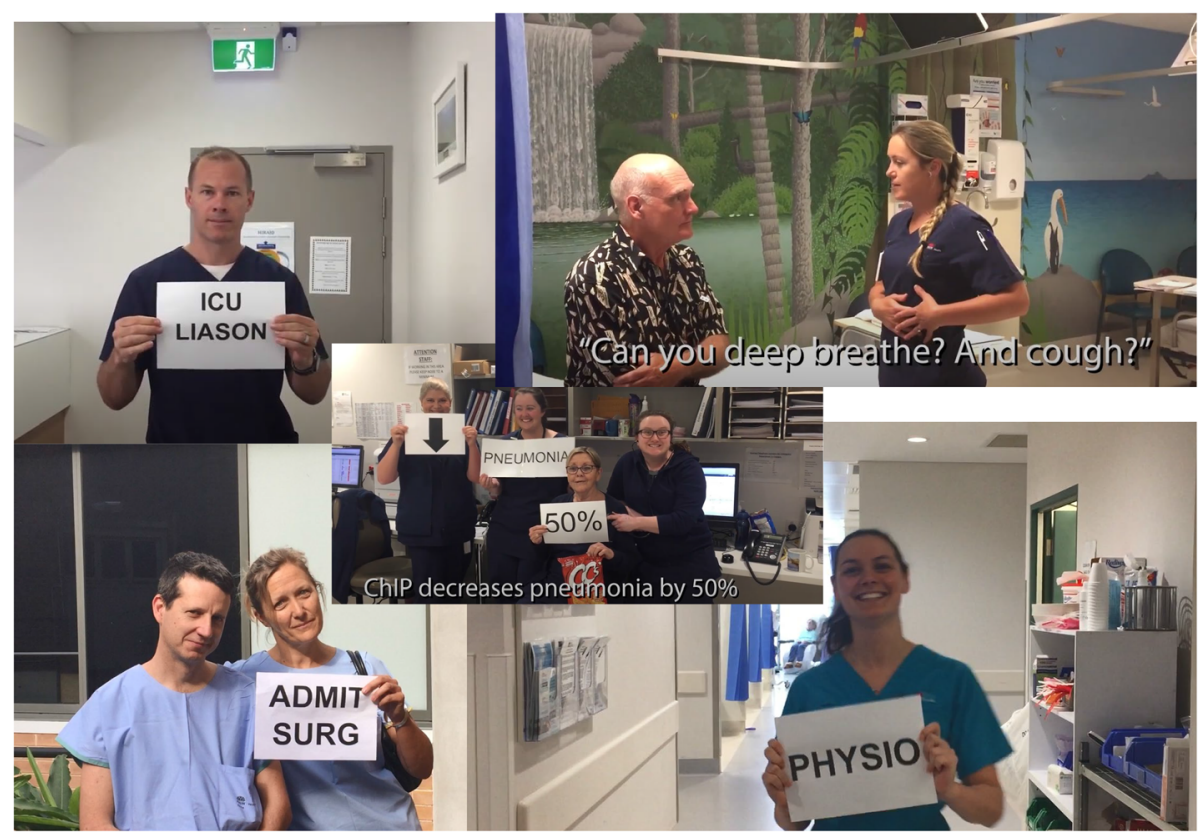

Fig. 2 Collage of stills from the ChIP video 
(ICU) liaison $\mathrm{CNC}$ to respond to ChIP activation calls and provide informal feedback to the implementation team on the response to ChIP.

Audits would follow a template looking for failure in the process for missed ChIP calls or inadequate ChIP responses. They were to be conducted monthly for 12 months. Identified problems would be flagged so that adjustments could be made to the plan if necessary. The audits would be communicated back to the implementation team and department managers regularly.

Education sessions Face-to-face education sessions addressed five of the BCTs and intervention functions education, persuasion, training, modelling, and enablement. The intervention development team prepared lesson plans and presentation slides for the educational sessions, which were adapted for the departments. The educational sessions were to be delivered to relevant staff by the ED CNCs and educators, ICU liaison for the wards, and senior physicians. All staff providing the educational sessions received the presentation slides and training from an investigator $(\mathrm{KC})$, an $\mathrm{ED} \mathrm{CNC}$.

Environmental changes Environmental changes addressed two BCTs and intervention function of environmental restructuring, education, and enablement. An icon was integrated into the electronic medical record software so staff from the emergency department could flag patients who had a ChIP activation. The icon was a chip packet the same as used on the advertisements.

High-flow oxygenation machines were secured through a grant from Fisher E Paykel and needed to be labelled with the ChIP policy and instructions for use. Incentive spirometry devices needed to be made available. Both of these items would need to be placed in easily accessible areas in the ED.

\section{Methods}

This evaluation study assessed fidelity of the implementation strategies for a blunt chest injury care bundle (ChIP) based on BCTs used in an implementation plan. This evaluation focused on implementation strategy fidelity by the site implementation teams (authors BM, $\mathrm{KC}, \mathrm{SB}, \mathrm{MW}$ ). Implementation team members at two hospital sites were asked to score BCT items to determine adherence to the implementation plan in the 30months since the initial implementation.

This study is part of a larger study testing the efficacy of the ChIP. Research conducted as part of this study adhered to the National Statement on Ethical Conduct in Human Research by the Australian National Health and Medical Research Council [28] and was approved by the NSW Population \& Health Services Research Ethics Committee (HREC/17/CIPHS/56). A STaRI (Standards for Reporting Implementation Studies) template has been completed along with this submission [see Additional file 2] [29].

\section{Context/setting}

ChIP implementation was carried out at two hospital sites in regional NSW, Australia, within the same local health district. Site 1 is a regional trauma centre seeing approximately 70,000 presentations annually, and site 2 is a smaller district hospital with about 40,000 presentations to its emergency department annually [30].

\section{Data collection}

To assess implementation strategy fidelity, each of the BCTs included as a part of the implementation plan, including the mechanism of action and mode of delivery, was retrospectively evaluated using a scoring system. This was assessed retrospectively to determine if what was planned by the implementation support team was implemented.

Four nurses responsible for leading implementation at the study sites (implementers) were questioned on the fidelity of the implementation plan with three implementers involved at each site. The implementers were the two district clinical nurse consultants (who were also familiar with intervention development at both sites), the clinical nurse educator of one the ED (site 2), and the ICU liaison who had also agreed to be a clinical champion (site 1). Implementers (KC, BM, MW, SB) individually completed an intervention fidelity scoring sheet electronically for each site (21 per site).

\section{Tool development}

There is no consensus on the evaluation of implementation fidelity in the literature [7], though researchers have been working towards a solution [14]. The BCW recommends using the BCTs in the implementation fidelity evaluation [6], which was attempted for this study. Two questions were included for each of the mechanism of action within each BCT. The first question was 'Were the behaviour change interventions implemented?' This was answered using a three-point scoring system. A score of 0 meant the strategy was 'not implemented', a score of 1 indicated it was partially implemented, and a score of 2 indicated the strategy was fully implemented. This first question aimed to establish adherence or dose to the mechanisms of action from the implementation plan $[9,15]$.

A second question for each item was 'Were adaptations made to the implementation plan?' This question was scored 1 (many changes from the plan) to 4 (just as planned) [31]. This question aimed to establish fidelity (adaptation) of programme delivery [9, 15]. Adaptation is vital to the implementation process as implementers 
need to adapt to the context [31]. Therefore, it is important to keep track of the implementation process and the adaptations made.

Participant responsiveness was not addressed as behaviour change was targeted at staff rather than patients.

The implementers were asked to comment with supporting evidence and documentation. Examples of documentation included emails, implementation checklists, audit reports, and incident reports.

\section{Analysis}

Data analysis was conducted by an independent researcher (SK) not involved in the onsite implementation. The analysis was performed using SPSS v25. Proportions were calculated for implementation and adaptation at each site and overall against each possible score. The quantitative data and supporting documentation data were compiled by an author (SK). The scores were compared by author (SK), and inconsistencies highlighted. The documentation sources were used to provide evidence for the score given and to evaluate discrepancies between scorers. It was also used to evaluate discrepancies between scorers. These inconsistencies were then discussed as a group where each implementer provided evidence as to why they gave their score. Discussions continued until consensus was reached. The documentation sources offered more information about the adaptations that were made.

\section{Results}

Overall, more than three quarters $(32 / 42,76.2 \%)$ of the mechanisms of action were fully implemented, with an additional 9/42 (21.4\%) partially implemented (Table 3). Only $1 / 42(2.4 \%)$ of mechanisms were reported as not implemented. Almost a quarter of mechanisms required adaptations-slight adaptations 10/42 (23.8\%) and 1/42 (2.4\%) some adaptation.

At site 1, 17/21 (81.0\%) of mechanisms of action were agreed to have been implemented in full (implementation scores of 2), with 16/21 (76.2\%) agreed to have been delivered as planned (adapt scores of 4). There were 4/ $21(19.0 \%)$ that were reported partially implemented, and $5 / 21(23.8 \%)$ that were reported to have slight adaptions from the plan (adapt score 3). At site 2, 15/21 (71.4\%) of the BCTs were implemented in full, 5/21 (23.8\%) were partially implemented, and $1 / 21(4.8 \%)$ was not implemented.

Most BCTs were considered to be fully implemented. BCTs that were not fully implemented were social support, feedback on behaviour, feedback on outcomes of behaviour, adding objects to the environment, and restructuring the environment (Table 1). The modes of delivery associated with the BCTs that were not fully implemented, clinical champions, audit/feedback, and environmental restructuring, are discussed further as to their fidelity and adaptations.

\section{The video}

Implementers agreed that the video was fully implemented across sites and was helpful. It was shown at the educational sessions and meetings and was also attached as a link in correspondence. Implementers reported that adaptations were made to the video to have two versions, one for each hospital site. Adaptations were also made to include the updated policy and include clips of how to prescribe high-flow oxygen as a treatment. Initially, there was some inconsistency in flow rates being administered.

\section{Facilitators/clinical champions}

Implementers reported that clinical champions were partially implemented. They stated there were issues with the clinical champions at both sites. Some staff volunteered to be clinical champions, were given a temporary contract, and were orientated to the role by the clinical nurse consultant. However, from the eight staff hired and trained, only one staff member at each site continued to be involved in the implementation. The implementers stated that adaptations were attempted with several recruitment rounds. Nevertheless, only two clinical champions continued. The implementers reported that both of these staff performed well and provided support, though not the level of support that was planned. The clinical nurse consultants, clinical nurse educators, and medical leads further supported them in the role of clinical champion.

\section{Audit and feedback}

Implementers at both sites reported audit and feedback were partially implemented. They reported that audit procedures were generated as per the implementation plan for the first 6 months post-implementation. During this time, the audits were run monthly using a standardised template and circulated to department heads. However, after this time, checks were less regular and only attended in response to feedback or random spot checks. The main concern from surgical and ICU registrars with the implementation was that there would be increased workload and the feedback helped allay these fears.

Implementers reported that feedback and audits were run in response to complaints or feedback. For example, a regular complaint received was that many patients were discharged from ED; however, reports were run demonstrating this happened $2 \%$ of the time, which was fed back to staff. Another example of feedback from ward staff was that the ED staff were not prescribing regular analgesia and were waiting for ICU or the pain 
Table 3 Behaviour change techniques, mechanisms of action in relation, and their reported implementation status and adaptations

\begin{tabular}{|c|c|c|c|c|}
\hline BCTs & $\begin{array}{l}\text { Intervention } \\
\text { functions }\end{array}$ & Mechanism of action & $\begin{array}{l}\text { Implementation } \\
\text { status }\end{array}$ & Adaptations \\
\hline 1.9. Commitment & $\begin{array}{l}\text { Incentivisation, } \\
\text { enablement }\end{array}$ & Staff appear in a video promoting ChIP & Full & $\mathrm{Nil}$ \\
\hline $\begin{array}{l}\text { 2.2. Feedback on } \\
\text { behaviour }\end{array}$ & $\begin{array}{l}\text { Education, } \\
\text { persuasion, } \\
\text { incentivisation }\end{array}$ & $\begin{array}{l}\text { Staff compliance monitored through audits and staff will be } \\
\text { informed of the results informally by clinical champions, through } \\
\text { newsletters and emails }\end{array}$ & Partial & Minor \\
\hline $\begin{array}{l}\text { 2.7. Feedback on } \\
\text { outcome(s) of } \\
\text { behaviour }\end{array}$ & $\begin{array}{l}\text { Education, } \\
\text { incentivisation, } \\
\text { training }\end{array}$ & $\begin{array}{l}\text { Feedback given to staff from audit results on patients treated } \\
\text { with the care bundle through clinical champions }\end{array}$ & Full & $\mathrm{Nil}$ \\
\hline 3.1. Social support & Enablement & $\begin{array}{l}\text { Clinical champions chosen from each area receive extra training } \\
\text { to be able to provide extra support }\end{array}$ & Partial & Minor \\
\hline $\begin{array}{l}\text { 4.1. Instruction on } \\
\text { how to perform } \\
\text { behaviour }\end{array}$ & Training & $\begin{array}{l}\text { Staff receive instructions on behaviour via a video, educational } \\
\text { sessions, and clinical champions }\end{array}$ & Full & $\mathrm{Nil}$ \\
\hline $\begin{array}{l}\text { 5.1. Information } \\
\text { about health } \\
\text { consequences }\end{array}$ & $\begin{array}{l}\text { Education, } \\
\text { persuasion }\end{array}$ & $\begin{array}{l}\text { Staff informed about the improvement in pneumonia rates } \\
\text { reduction with the protocol from previous study through video, } \\
\text { educational sessions, flyers, newsletters, and emails }\end{array}$ & Full & $\mathrm{Nil}$ \\
\hline $\begin{array}{l}\text { 6.1. Demonstration } \\
\text { of behaviour }\end{array}$ & $\begin{array}{l}\text { Training, } \\
\text { modelling }\end{array}$ & $\begin{array}{l}\text { Staff receive demonstrations of behaviour via a video, } \\
\text { educational sessions, and clinical champions }\end{array}$ & Full & Minor \\
\hline $\begin{array}{l}\text { 6.3. Information } \\
\text { about others' } \\
\text { approval }\end{array}$ & $\begin{array}{l}\text { Education, } \\
\text { persuasion }\end{array}$ & Local staff appear in the ChIP video showing support & Full & $\mathrm{Nil}$ \\
\hline \multirow[t]{2}{*}{ 7.1. Prompts/cues } & $\begin{array}{l}\text { Education, } \\
\text { environmental } \\
\text { restructuring }\end{array}$ & $\begin{array}{l}\text { A visual prompt (screen icon) developed for the electronic } \\
\text { medical record to flag to staff that patient is eligible for care } \\
\text { bundle }\end{array}$ & Full & Minor \\
\hline & & $\begin{array}{l}\text { Flyers put up around the workplace to remind staff of the care } \\
\text { bundle }\end{array}$ & Full & $\mathrm{Nil}$ \\
\hline 8.3. Habit formation & Training & $\begin{array}{l}\text { Staff encouraged to assess all potentially eligible patients } \\
\text { systematically in the video and educational sessions }\end{array}$ & Full & $\mathrm{Nil}$ \\
\hline 9.1. Credible source & Persuasion & $\begin{array}{l}\text { Senior local staff appear in a video informing staff about and } \\
\text { promoting ChIP }\end{array}$ & Full & Nil \\
\hline \multirow[t]{4}{*}{$\begin{array}{l}\text { 12.1. Restructuring } \\
\text { the physical } \\
\text { environment }\end{array}$} & $\begin{array}{l}\text { Environmental } \\
\text { restructuring, } \\
\text { enablement }\end{array}$ & $\begin{array}{l}\text { Equipment necessary for ChIP placed in a location that ensures } \\
\text { ease of access }\end{array}$ & Full & $\mathrm{Nil}$ \\
\hline & & Equipment adequately labelled with instructions & Partial & Minor \\
\hline & & $\begin{array}{l}\text { Additional equipment supplied to ensure adequate supply (high- } \\
\text { flow machines and incentive spirometry) }\end{array}$ & Partial & Minor \\
\hline & & ChIP tested by staff to ensure ease of use & Full & Nil \\
\hline \multirow[t]{2}{*}{$\begin{array}{l}\text { 12.5. Adding objects } \\
\text { to the environment }\end{array}$} & $\begin{array}{l}\text { Environmental } \\
\text { restructuring, } \\
\text { enablement }\end{array}$ & $\begin{array}{l}\text { An icon added for the electronic medical record to flag to staff } \\
\text { that patient is eligible for care bundle }\end{array}$ & Full & Nil \\
\hline & & A pager setup to be able to contact staff responding to ChIP & $\begin{array}{l}\text { Full at one site, } \\
\text { not at all at } \\
\text { second site }\end{array}$ & $\begin{array}{l}\text { Major adaptation } \\
\text { required at the } \\
\text { small site }\end{array}$ \\
\hline $\begin{array}{l}\text { 13.1. Identification } \\
\text { of self as role model }\end{array}$ & $\begin{array}{l}\text { Persuasion, } \\
\text { enablement }\end{array}$ & $\begin{array}{l}\text { Staff asked to volunteer for the roles of clinical champions and } \\
\text { to be in the video }\end{array}$ & Full & Nil \\
\hline $\begin{array}{l}\text { 15.1. Verbal } \\
\text { persuasion about } \\
\text { capability }\end{array}$ & $\begin{array}{l}\text { Persuasion, } \\
\text { enablement }\end{array}$ & $\begin{array}{l}\text { Staff encouraged during educational sessions and by clinical } \\
\text { champions that they are capable of following ChIP }\end{array}$ & Full & $\mathrm{Nil}$ \\
\hline
\end{tabular}

service to chart prescriptions-leading to delays in analgesia delivery. To prevent this from continuing to occur, additional reinforcement of the role of the ED in charting analgesia was required, especially with the change in terms and rotations.
Another adaptation reported was that the audit process was incorporated into the role of the 'between the flags' $\mathrm{CNC}$ who already reviews cases of unplanned ICU admissions. This role has continued past the implementation team involvement. 


\section{Environmental changes}

Implementers reported some issues and need for adaptations with the implementation of some environmental changes. For example, implementers reported that though the high-flow oxygenation machines were labelled with the ChIP policy, this was insufficient to the implementation as they should have also been labelled with information for the use of the machines.

Implementers reported that adaptations were made to the type of incentive spirometers ordered per requests from the physiotherapy department. Implementers reported that physiotherapists preferred to use volumedriven incentive spirometers which ED did not have in stock. As the volume-driven spirometers were an evidence-based option, the new spirometers were ordered.

At the smaller hospital, implementers reported significant changes to the implementation plan for the paging system. It was identified that the majority of the responders did not use their pagers which was not identified during the barrier identification phase. Pagers were not used for a notification system as it was found that the responders did not carry them. The system had to be changed so that the ED staff would put an order through the electronic medical system. Activating it in this way gave activating staff a list with contacts to call.

An example of an adaptation led by participants was from the ortho-geriatric team who were concerned ChIP patients were being referred to them overnight by the emergency department but then not handed over to them in the mornings. The team came up with a solution, which they bought to the implementation team. They wanted to keep the pager in a common area where it could be easily accessed after a night shift with a sign reminding staff of the criteria.

\section{Discussion}

This study describes the evaluation of implementation strategy fidelity in the acute care context. Implementation studies should include evaluation of implementation fidelity to avoid a type III error, where we may assume an intervention does not work, but it was not implemented effectively [32]. Methods for evaluation of implementation strategy fidelity are still in development [7]. Successful translation of evidence into practice requires effective mechanisms of action or implementation strategies; however, these have been inconsistently reported in the literature. There are multiple taxonomies for developing implementation strategies in the literature, making consistency difficult $[23,33]$. A strength of this study was that the strategies used were theory-driven, and these were used to inform the evaluation [13]. Subsequently, the theory-driven mechanisms of action were used to inform the evaluation.
The majority of action items were scored as partially or fully implemented (97.6\%), considered high fidelity [24]. A summary of the complex relationship between intervention functions, BCTs, and modes of delivery has been collated in a logic map (Fig. 3). Filled boxes represent BCTs or modes that were fully implemented, and partially filled boxes represent BCTs or modes of delivery partially completed in the implementation. The main modes of delivery used were educational sessions, video, clinical champions, advertisements, audit and feedback, and environmental changes. As there is overlap with some of the BCTs addressing the same intervention functions, all intervention functions were still addressed even if not all modes were fully implemented.

Adaptations are integral to the implementation process and should be recorded, and there were no predetermined restrictions to adaptations in this study [34]. Overall, the sites were very similar in the results. The smaller, rural site required more adaptations, needing a complete overhaul of the paging system to change to phone calls. Adaptations are a natural part of the implementation process; however, they need to be documented [35]. For example, the audits were discontinued; however, the audits were adapted to be part of the role of the existing CNCs. This adaptation is an example of an intervention becoming embedded in the system and leading to sustainability [36].

This study had limitations. It was difficult to find a framework to fit the acute care context impacting the rigour of analysis and conclusions. Frameworks exist for the evaluation of implementation fidelity [14]; however, the focus of these frameworks is often patient or client behaviours or the fidelity of delivery rather than the plan $[9,16,37]$. Evaluators need to be wary of using frameworks with an inappropriate focus, such as community compared to acute care [13]. The implementation of ChIP was within the hospital organisational system; to our knowledge, there are limited evaluations in this setting. The implementation strategies targeted the behaviour of staff involved in the activation or response to ChIP. There is a need for conceptual frameworks that evaluate implementation at the organisational level of healthcare to support implementation targeting staff change $[7,13]$. Though a framework was used, the authors found the implementation outcomes were still not as specific as needed for the evaluation; future implementation plans should include a plan for how implementation strategy fidelity will be evaluated [25].

Retrospective completion of the scoring by the implementers relied somewhat on the memory of the implementers, which may be lacking. To counterbalance this, implementers were asked to supplement with documentation where possible (their log/audit records). Furthermore, the implementers completed the scoring 


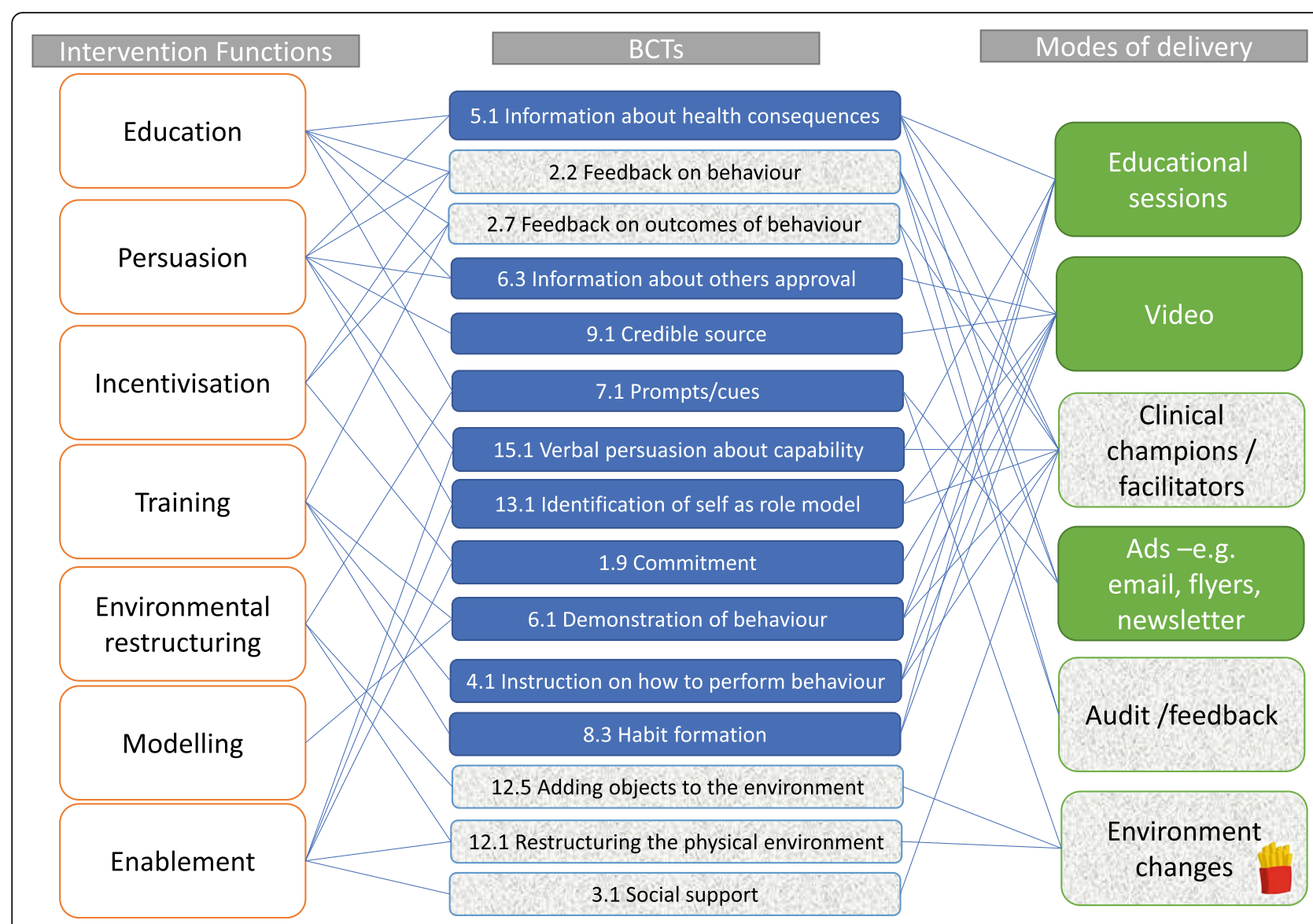

Fig. 3 Logic map of intervention functions, BCTs, and modes of delivery for the ChIP implementation. Block colour indicates fully implemented BCTs and modes whereas shaded colour indicated partially implemented

separately so there would not be compromised results by relying on other opinions. Unfortunately, due to the small sample size, it was difficult to report on inter-rater agreement. The development of fidelity assessment criteria is another way to evaluate implementation strategy fidelity, which should be considered in implementation development rather than retrospective review [38].

It was a limitation that we could not fully report on the dose of the implementation strategy fidelity, which is the 'proportion of intervention providers who received the implementation strategies' [7], as it was difficult to evaluate the dose with confidence retrospectively. The dose would have included reporting how many staff members were reached with the various modes of delivery. However, with an implementation plan of this magnitude involving many layers of strategy, even prospectively, it would have been difficult to assess for dose. For example, the video was viewed by staff accessing the link themselves, but the video was also shown to large groups in education sessions, making it difficult to assess the true reach. Likewise, the flyers were posted in common areas, and other advertising materials were posted in the newsletter or emails. Even if we could identify staff who received the emails, it would be almost impossible to know the proportion of staff who engaged with these materials.

This study evaluates the implementation strategy fidelity for ChIP. This will help inform implementation in the emergency or multidisciplinary context. Planning for implementation includes consideration of the context of implementation and adaptations required at each site.

\section{Conclusion}

This study evaluated two aspects of the fidelity of an implementation plan-the degree of implementation and the adaptations made. The findings indicated that implementation strategy fidelity might be assessed retrospectively from implementation documentation using a structured process evaluating behaviour change interventions. Adaptations to the implementation plan at one site may not be required at another site. A fidelity checklist developed during the implementation process may help implementers assess fidelity. 


\section{Abbreviations}

BCT: Behaviour change technique; BCW: Behaviour Change Wheel; ChIP: Chest Injury Protocol; CNC: Clinical nurse consultant; ED: Emergency department; ICU: Intensive care unit

\section{Supplementary Information}

The online version contains supplementary material available at https://doi. org/10.1186/s43058-021-00189-8

Additional file 1. Implementation plan - redacted.

Additional file 2. StaRI checklist.

\section{Acknowledgements}

The authors would like to acknowledge the staff from the Illawarra Shoalhaven Local Health District and Judith Fethney.

\section{Authors' contributions}

All authors made substantial contributions to the conception and design of the study. SK, KC, and BM were involved in the study design. SK, KC, and BM were involved in the question design. $\mathrm{KC}, \mathrm{BM}, \mathrm{MW}$, and SB made a substantial contribution to the acquisition of the data. SK did the quantitative analysis. SK and KC drafted the manuscript, and KC, BM, MW, TB, and $\mathrm{SB}$ authors have been involved in substantively revising the work critically. SK, KC, BM, MW, TB, and SB authors have read and approved the final manuscript for publication.

\section{Authors' information}

$\mathrm{KC}$ and $\mathrm{BM}$ are district clinical nurse consultants for the hospital area local health district. SB is the clinical nurse educator for the Shoalhaven Memorial District Hospital emergency department, and MW is an ICU clinical liaison nurse.

\section{Funding}

This research has been supported by funding from the HCF Research Foundation (AU). SK is funded by a scholarship from the HCF Research Foundation (AU).

\section{Availability of data and materials}

The data supporting the conclusions of this article are included within the article. The individual data sets used in the evaluation are available from the corresponding author on reasonable request.

\section{Declarations}

\section{Ethics approval and consent to participate}

This study is part of a larger study testing the efficacy of the care bundle (ChIP). Research conducted as part of this study adhered to the National Statement on Ethical Conduct in Human Research by the Australian National Health and Medical Research Council (NHMRC, 2018) and was approved by the NSW Population \& Health Services Research Ethics Committee (HREC/17/ CIPHS/56).

\section{Consent for publication}

Images of participants from the video stills have provided consent for their images to be used.

\section{Competing interests}

The authors declare that they have no competing interests.

\section{Author details}

${ }^{1}$ Faculty of Medicine and Health, Sydney Nursing School, The University of Sydney Susan Wakil School of Nursing and Midwifery, 88 Mallet St, Camperdown, NSW, Australia. ${ }^{2}$ Director of Critical Care Research, Illawarra Shoalhaven Local Health District, Warrawong, Australia. ${ }^{3}$ Illawarra Health and Medical Research Institute, University of Wollongong, Wollongong, NSW, Australia. ${ }^{4}$ Emergency Services, Illawarra Shoalhaven Local Health District, Wollongong Hospital, Crown St, Wollongong, NSW, Australia. ${ }^{5}$ Intensive Care, Illawarra Shoalhaven Local Health District, Wollongong Hospital, Crown St,
Wollongong, NSW, Australia. ${ }^{6}$ Emergency Services, Shoalhaven Memorial District Hospital, Shoalhaven, NSW, Australia.

Received: 22 October 2020 Accepted: 25 July 2021

Published online: 10 August 2021

\section{References}

1. Battle $C E$, Hutchings $H$, Evans PA. Risk factors that predict mortality in patients with blunt chest wall trauma: a systematic review and metaanalysis. Injury. 2012;43(1):8-17. https://doi.org/10.1016/j.injury.2011.01.004.

2. Kourouche S, Buckley T, Munroe B, Curtis K. Development of a blunt chest injury care bundle: an integrative review. Injury. 2018;49(6):1008-23. https:// doi.org/10.1016/j.injury.2018.03.037.

3. Michie S, van Stralen MM, West R. The behaviour change wheel: a new method for characterising and designing behaviour change interventions. Implement Sci. 2011;6(1):42.

4. Cane J, O'Connor D, Michie S. Validation of the theoretical domains framework for use in behaviour change and implementation research. Implement Sci. 2012;7(1):37.

5. DeVon HA, Patmon FL, Rosenfeld AG, Fennessy MM, Francis D. Implementing clinical research in the high acuity setting of the emergency department. J Emerg Nursing. 2013;39(1):6-12. https://doi.org/10.1016/j.jen.2 012.08.012.

6. Michie S, Atkins L, West R. The behaviour change wheel: a guide to designing interventions. London: Silverback Publishing; 2014.

7. Slaughter SE, Hill JN, Snelgrove-Clarke E. What is the extent and quality of documentation and reporting of fidelity to implementation strategies: a scoping review. Implement Sci. 2015;10(1):129. https://doi.org/10.1186/s13 012-015-0320-3

8. McGee D, Lorencatto F, Matvienko-Sikar K, Toomey E. Surveying knowledge, practice and attitudes towards intervention fidelity within trials of complex healthcare interventions. Trials. 2018;19(1):504. https://doi.org/10.1186/s13 063-018-2838-6.

9. Carroll C, Patterson M, Wood S, Booth A, Rick J, Balain S. A conceptual framework for implementation fidelity. Implement Sci. 2007;2(1):40. https:// doi.org/10.1186/1748-5908-2-40.

10. Walton H, Spector A, Tombor I, Michie S. Measures of fidelity of delivery of, and engagement with, complex, face-to-face health behaviour change interventions: a systematic review of measure quality. $\mathrm{Br} J$ Health Psychol. 2017;22(4):872-903. https://doi.org/10.1111/bjhp.12260.

11. Cross WF, West JC. Examining implementer fidelity: conceptualizing and measuring adherence and competence. J Child Serv. 2011;6(1):18-33. https://doi.org/10.5042/jcs.2011.0123.

12. Dogar O, Boehnke JR, Lorencatto F, Sheldon TA, Siddiqi K. Measuring fidelity to behavioural support delivery for smoking cessation and its association with outcomes. Addiction. 2020;115(2):368-80. https://doi.org/10.1111/a dd. 14804

13. Moore GF, Audrey S, Barker M, Bond L, Bonell C, Hardeman W, et al. Process evaluation of complex interventions: Medical Research Council guidance. Bmj. 2015;350(mar19 6):h1258. https://doi.org/10.1136/bmj.h1258.

14. Roy R, Colquhoun H, Byrne M, Lorencatto F, Matvienko-Sikar K, Mccleary N, et al. Addressing fidelity within complex health behaviour change interventions: a protocol of a scoping review of intervention fidelity frameworks and models. HRB Open Res. 2018;1(25). https://doi.org/10.12 688/hrbopenres.12892.1

15. Ibrahim S, Sidani S. Intervention fidelity in interventions: an integrative literature review. Res Theory Nurs Pract. 2016;30(3):258-71. https://doi.org/1 0.1891/1541-6577.30.3.258

16. Bellg AJ, Borrelli B, Resnick B, Hecht J, Minicucci DS, Ory M, et al. Enhancing treatment fidelity in health behavior change studies: best practices and recommendations from the NIH Behavior Change Consortium. Health Psychol. 2004;23(5):443-51. https://doi.org/10.1037/0278-6133.23.5.443.

17. Century J, Rudnick M, Freeman C. A framework for measuring fidelity of implementation: a foundation for shared language and accumulation of knowledge. Am J Eval. 2010;31(2):199-218. https://doi.org/10.1177/1098214 010366173.

18. Curtis K. Trial registration: Retrospective pre-post evaluation of the impact of an evidence-based protocol for management of patients with blunt chest injury under real-world conditions: Chest Injury bundle of care Protocol (ChIP). 2018. https://www.anzctr.org.au/Trial/Registration/TrialReview.a spx?id=375961\&isReview=true 
19. Kourouche S, Curtis K, Munroe B, Asha SE, Carey I, Considine J, et al. Implementation of a hospital-wide multidisciplinary blunt chest injury care bundle (ChIP): fidelity of delivery evaluation. Aust Crit Care. 2021. https:// doi.org/10.1016/j.aucc.2021.04.003

20. Curtis K, Asha SE, Unsworth A, Lam M, Goldsmith H, Langcake M, et al. ChIP: an early activation protocol for isolated blunt chest injury improves outcomes, a retrospective cohort study. Aust Emerg Nurses J. 2016;19(3): 127-32. https://doi.org/10.1016/j.aenj.2016.06.002.

21. Lavallée JF, Gray TA, Dumville J, Russell W, Cullum N. The effects of care bundles on patient outcomes: a systematic review and meta-analysis. Implement Sci. 2017;12(1):142. https://doi.org/10.1186/s13012-017-0670-0.

22. Kourouche S, Buckley T, Van C, Munroe B, Curtis K. Designing strategies to implement a blunt chest injury care bundle using the behaviour change wheel: a multi-site mixed methods study. BMC Health Serv Res. 2019;19(1): 461. https://doi.org/10.1186/s12913-019-4177-z.

23. Michie S, Richardson M, Johnston M, Abraham C, Francis J, Hardeman W. The behavior change technique taxonomy (v1) of 93 hierarchically clustered techniques: building an international consensus for the reporting of behavior change interventions. Ann Behav Med. 2013;46(1):81-95. https:// doi.org/10.1007/s12160-013-9486-6.

24. Lorencatto F, West R, Christopherson C, Michie S. Assessing fidelity of delivery of smoking cessation behavioural support in practice. Implement Sci. 2013;8(1):40. https://doi.org/10.1186/1748-5908-8-40.

25. Proctor $E$, Silmere $H$, Raghavan $R$, Hovmand $P$, Aarons G, Bunger A, et al. Outcomes for implementation research: conceptual distinctions, measurement challenges, and research agenda. Adm Policy Ment Health. 2011;38(2):65-76. https://doi.org/10.1007/s10488-010-0319-7.

26. Proctor EK, Powell BJ, McMillen JC. Implementation strategies: recommendations for specifying and reporting. Implement Sci. 2013;8(1): 139. https://doi.org/10.1186/1748-5908-8-139.

27. Harvey G, Kitson A. PARIHS revisited: from heuristic to integrated framework for the successful implementation of knowledge into practice. Implement Sci. 2016;11(1):33.

28. National Health and Medical Research Council (NHMRC). The National Statement on Ethical Conduct in Human Research 2017 (updated 2018). Australia: Australian government; 2018.

29. Pinnock H, Barwick M, Carpenter CR, Eldridge S, Grandes G, Griffiths CJ, et al. Standards for Reporting Implementation Studies (StaRI) statement. BMJ. 2017;356:i6795.

30. The Bureau of Health Information. Healthcare observer 2019 [updated 07/ 11/19]. Available from: http://www.bhi.nsw.gov.au/Healthcare_Observer.

31. Dariotis JK, Bumbarger BK, Duncan LG, Greenberg MT. How do implementation efforts relate to program adherence? Examining the role of organizational, implementer, and program factors. Am J Community Psychol. 2008;36(6):744-60. https://doi.org/10.1002/jcop.20255.

32. Hasson $\mathrm{H}$. Systematic evaluation of implementation fidelity of complex interventions in health and social care. Implement Sci. 2010;5(1):67. https:// doi.org/10.1186/1748-5908-5-67.

33. Powell BJ, Waltz TJ, Chinman MJ, Damschroder LJ, Smith JL, Matthieu MM, et al. A refined compilation of implementation strategies: results from the Expert Recommendations for Implementing Change (ERIC) project. Implement Sci. 2015;10(1):21. https://doi.org/10.1186/s13012-015-0209-1.

34. Wiltsey Stirman S, Baumann AA, Miller CJ. The FRAME: an expanded framework for reporting adaptations and modifications to evidence-based interventions. Implement Sci. 2019;14(1):58. https://doi.org/10.1186/s13012019-0898-y.

35. Escoffery C, Lebow-Skelley E, Haardoerfer R, Boing E, Udelson H, Wood R, et al. A systematic review of adaptations of evidence-based public health interventions globally. Implement Sci. 2018;13(1):125. https://doi.org/10.11 86/s13012-018-0815-9.

36. Martin GP, Weaver S, Currie G, Finn R, McDonald R. Innovation sustainability in challenging health-care contexts: embedding clinically led change in routine practice. Health Serv Manag Res. 2012;25(4):190-9. https://doi.org/1 $0.1177 / 0951484812474246$.
37. Harden SM, Gaglio B, Shoup JA, Kinney KA, Johnson SB, Brito F, et al. Fidelity to and comparative results across behavioral interventions evaluated through the RE-AIM framework: a systematic review. Syst Rev. 2015;4(1):155. https://doi.org/10.1186/s13643-015-0141-0.

38. Stockdale SE, Hamilton AB, Bergman AA, Rose DE, Giannitrapani KF, Dresselhaus TR, et al. Assessing fidelity to evidence-based quality improvement as an implementation strategy for patient-centered medical home transformation in the Veterans Health Administration. Implement Sci. 2020;15(1):18. https://doi.org/10.1186/s13012-020-0979-y.

\section{Publisher's Note}

Springer Nature remains neutral with regard to jurisdictional claims in published maps and institutional affiliations.
Ready to submit your research? Choose BMC and benefit from:

- fast, convenient online submission

- thorough peer review by experienced researchers in your field

- rapid publication on acceptance

- support for research data, including large and complex data types

- gold Open Access which fosters wider collaboration and increased citations

- maximum visibility for your research: over $100 \mathrm{M}$ website views per year

At $\mathrm{BMC}$, research is always in progress.

Learn more biomedcentral.com/submissions 